\title{
Investigating the association between chronological age and thyroid cartilage ossification using CT imaging
}

\author{
Seyed Morteza Tabatabaee ${ }^{1}$, Maryam Vasheghani Farahani*2 ${ }^{\mathbb{1}}$, Alimohammad Alimohammadi³ ${ }^{3}$ Babak Shekarchi ${ }^{4}$
}

Received: 14 May 2019

Published: 5 Oct 2020

\section{Abstract}

Background: Thyroid cartilage ossifies through time. In addition to different methods for age estimation, ossified volume can be a valuable index for age estimation. In this study, anthropometric characteristics and ossified volume were measured using CT scan imaging to find potential correlations between measures and age.

Methods: In this study, 100 thyroid cartilage of Iranian corpses (60 men and 40 women) were studied. Corpses from Kahrizak hall of Tehran Legal Medicine Organization were included in this study. After obtaining required consent from their family, their thyroid cartilage was separated by an expert, and anthropometric properties of the cartilage were recorded. A 64-slice Siemens CT scan machine was used to measure specimen ossified volume and Hounsfield score by 3D reconstruction of images. Pearson's correlation test was used to measure the correlation between thyroid calcified volume and chronological age. Repeated measurement ANOVA test was also used to measure the correlation of the ossified volume and Hounsfield score with different age groups. SPSS version 22 was used for statistical analysis, and significance level was set at than 0.05 .

Results: All thyroid cartilage measures were higher in men than in women, except for thyroid angle, and the differences were statistically significant. Height of the laminae $(R=0.23, p=0.023)$ and depth of the thyroid notch $(R=0.198, p=0.049)$ were correlated with age. Mean ossified volume $(6.1 \pm 1.7 \mathrm{cc})$ and Hounsfield score $(308.8 \pm 53.5 \mathrm{HU})$ were directly correlated with age $(\mathrm{R}=0.205 ; \mathrm{p}=0.040$ and $\mathrm{R}=0.219 ; \mathrm{p}=0.029$, respectively), but none of these two radiologic parameters were correlated with age groups ( $\mathrm{p}=0.331$ and 0.063 , respectively). No specific ossification pattern was obtained from CT images in different age groups.

Conclusion: A combination of anthropometric measures such as the height of the laminae and depth of the thyroid notch with CT scan imaging measures such as ossified volume and the Hounsfield score are useful to estimate age with low precision. In addition, thyroid cartilage measures are useful for sex determination.

Keywords: Forensic science, Age estimation, Thyroid cartilage ossification, CT scan

Conflicts of Interest: None declared

Funding: AJA University of Medical Sciences

*This work has been published under CC BY-NC-SA 1.0 license.
Copyright $\subseteq \underline{\text { Iran University of Medical Sciences }}$

Cite this article as: Tabatabaee SM, Vasheghani Farahani M, Alimohammadi A, Shekarchi B. Investigating the association between chronological age and thyroid cartilage ossification using CT imaging. Med J Islam Repub Iran. 2020 (5 Oct);34:130. https://doi.org/10.47176/mjiri.34.130

\section{Introduction}

Identification is one of the important topics in forensic

Corresponding author: DrMaryam Vasheghani Farahani, vasheghani_m@yahoo.com

1. AJA University of medical sciences, Tehran, Iran

2. Department of Forensic Medicine and Clinical Toxicology, AJA University of Medical Sciences, Tehran, Iran

3. Legal Medicine Organization of Iran, Tehran, Iran

4. Department of Radiology, School of Medicine, AJA University of Medical Sciences, Tehran, Iran medicine, which depends on multiple factors such as age,

$\uparrow$ What is “already known” in this topic:

Unlike other cartilages, thyroid cartilage ossification starts after puberty. CT imaging can demonstrate the amount and pattern of ossification. Cartilage ossified volume and Hounsfield score measured by CT imaging can be a valuable index for age estimation.

\section{$\rightarrow$ What this article adds:}

Although all thyroid cartilage measures are useful for sex determination, the height of the laminae and depth of the thyroid notch are the only measurements that help age estimation. CTscan measures such as ossified volume and the Hounsfield score are useful in estimating age with low precision. 
gender, and descent; however, age estimation is the most challenging factor in this field (1). In the past few years, multiple methods have been developed due to increasing number of cadavers and people with unknown birthday information (2). Bone evolution of wrist, teeth evolution, palatal sutures, and the stages of erosion on the pubic symphyses are the most considerable approaches in this field $(3,4)$. Due to confounders such as interpersonal differences, using a single method may be inappropriate and it is necessary to use a combination of different methods to estimate age (5).

Morphometric characteristics of laryngeal cartilages have been surveyed in different studies $(6,7)$. Although using anthropometric features of thyroid cartilage in identification is not routine, the role of thyroid cartilage features in sex determination has been shown in other studies $(8,9)$. However, its unique features lead researchers to use this cartilage in the field of age estimation. Most of the cartilages in growth plates close after puberty, but in some of them, especially thyroid cartilage, ossification starts after puberty and stops after a special age (10). These changes probably begin from the second decade of life from the inferior horn of the thyroid cartilage and spread to other cartilage plates through the life time (11). Studies of the ossification in laryngeal cartilages, especially in thyroid cartilage, and their association with age have been surveyed in various communities. In 1983, a method was introduced to estimate the age based on thyroid cartilage ossification, but it was not supported by other studies which mostly used radiographic methods $(12,13)$. Histological studies in the process of the mineralization of the thyroid cartilage provide little information for researchers. Given the results that Keen and Wainwright gained, endochondral ossification forms bone within the laryngeal cartilage, which is called chondroid bone (11-13). However, radiological studies, despite their considerable number, could not provide accurate and determinant information for researchers. More accurate imaging methods such as CT scanning can demonstrate the pattern of thyroid cartilage ossification, which has gained attention in recent studies.

Due to the lack of enough investigations on thyroid car- tilage ossification through accurate methods and its efficacy, this study was designed to investigate the relationship between age and detectable changes of the thyroid cartilage ossification using CT scan in addition to anthropometric features of this cartilage.

\section{Methods}

Cases were selected from those dissected in Kahrizak Hall of Tehran since January 2018 until December 2018 who were meeting study criteria. Kahrizak is the main dissection Hall of Tehran Legal Medicine Organization, which is related to judicial system of Iran. All Iranian bodies over 20 years who were not dead due to any neck trauma such as fracture, hanging, penetrating trauma, or structural and congenital deformity were included. The study and its methodology were approved ethically by the AJA University of Medical Sciences, with approval ID of IR.AJAUMS.REC.1397.029.

After gaining required consent from the families, thyroid cartilage of the cases was separated using a Y-shaped incision to avoid any tissue damage by an expert working in the dissection hall. The rest of the attached tissues were removed and after measuring demographic and anthropometric properties, were stored in $10 \%$ formalin solution (which does not resolve the calcified tissue). To avoid tissue alteration and obtaining optimum radiographic results, the time between removing the tissue and performing CT imaging did not exceed 10 days. Gender, age, weight, height, and the reason of death were recorded as demographic information. Anthropometric measurements of thyroid cartilage was recorded based on Eckel study immediately after removal of the cartilage (14). Cartilage right and left laminae height (a), right and left laminae breadth (b), anterior border height (c), right and left total height (d), upper width (e), lower width (f), right and left superior horn (g), right and left inferior horn (h), thyroid notch depth (i), and thyroid angle (j) were measured using a $15-\mathrm{cm}$ digital caliper and goniometer (Fig. 1). To avoid too much numbers, only the average of right and left cartilage measurements was presented.
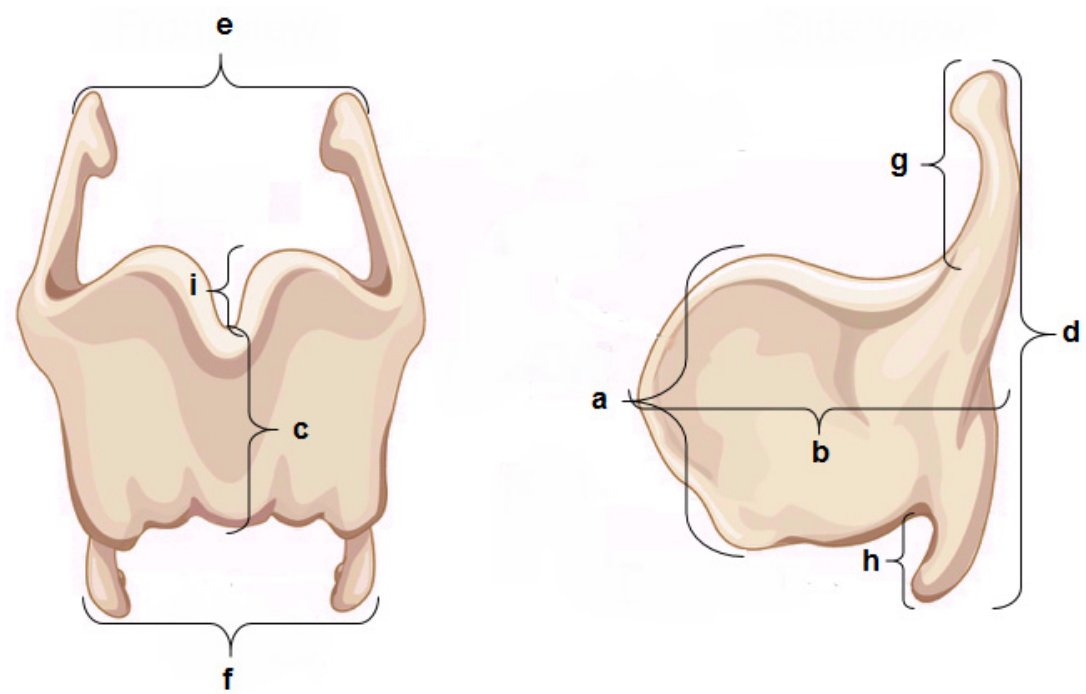

Fig. 1. Schematic image of anterior and lateral thyroid cartilage views explaining how measurements are done based on Eckel study (14). 
A 64-slice Siemens CT scan machine was used to measure specimen ossification. CT settings for this exam included tube voltage: $80 \mathrm{kVp}$, tube current: $42 \mathrm{~mA}$, rotation time: $1 \mathrm{~s}$, section thickness: $0.8 \mathrm{~mm}$, field of view: $296 \mathrm{~mm}$, image matrix: 512 pixels, filter: standard, window wide: 250, window level: 50, range: from the thyroid. Three-dimensional reconstruction and volume calculation were done by Siemens workstation. Volume was calculated using calcification Hounsfield, which was considered to be130 HU to $1000 \mathrm{HU}$. Because formalin density was lower than ossification Hounsfield and extra tissue was removed, no more picture process was needed and mean cartilage volume and Hounsfield score were directly provided through tables. All specimen were disposed through hospital pathological waste disposal protocol.

All data presented as mean \pm SD. Pearson's correlation test were used to measure the correlation of thyroid calcified volume and chronological age. Repeated measurement ANOVA test was also used to measure the correlation of the ossified volume and Hounsfield score with different age groups. SPSS version 22 was used for data analysis. Significance level was set at less than 0.05 .

\section{Results}

A total of 100 thyroid cartilage of Iranian corpses (60 men and 40 women) were assessed. Although the difference between men and women's weight $(76 \pm 11 \mathrm{~kg}$ vs $68 \pm$ $8 \mathrm{~kg} ; \mathrm{p}<0.001)$ and height $(174 \pm 5 \mathrm{~cm}$ vs $166 \pm 4 \mathrm{~cm}$; $\mathrm{p}<0.001)$ was significant, their mean BMI (25 \pm 2 vs $24 \pm 2$; $\mathrm{p}=0.396$ ) was the same.

Mean measures of the thyroid cartilage in both genders and mean differences and their correlation with age are demonstrated in Table 1. All measures were higher in men than in women except for thyroid angle, and these differences were statistically significant. Of the thyroid cartilage measures, the height of the right laminae and depth of thyroid notch was correlated with both age and gender. Additional analysis based on age groups showed that in the fourth to seventh decades of life, all thyroid cartilage parameters can be used as a sex determiner, except thyroid angle.

Hounsfield score and total ossified volume were also measured in the samples using CT scan imaging. Mean ossified volume was $6.1 \pm 1.7 \mathrm{cc}$, which was the same for men and women $(6.1 \pm 1.7$ vs $6 \pm 1.8$, respectively, $p=0.793)$. The ossified volume was directly correlated with age $(\mathrm{R}=0.205$ and $\mathrm{p}=0.040)$ (Table 2). Although this correlation was significant in women $(\mathrm{R}=0.548, \mathrm{p}<0.001)$ (Fig. 2), there was no such association in men $(R=0.058$ and $p=0.652)$ (Fig. 3$)$. When grouping the ages to decades, there was an ascending pattern through the ossified volume and age group, except for the 70-79-year-old samples (Fig. 4). Nevertheless, the results of the repeated measurement analysis showed that this pattern was not statistically significant $(\mathrm{p}=0.331)$.

Mean Hounsfield score was $308.8 \pm 53.5$, which was the same for men and women $(310.2 \pm 53.5$ vs $306.7 \pm 54.2$, respectively, $\mathrm{p}=0.752)$. Mean Hounsfield score was directly correlated with age $(\mathrm{R}=0.219$ and $\mathrm{p}=0.029)$ (Table 2). Similar to ossified volume, this correlation was significant in women $(\mathrm{R}=0.380, \mathrm{p}=0.042)$, but it was not significant in men $(\mathrm{R}=0.151, \mathrm{p}=0.257)$. The ascending pattern of age was seen in 20-59- year-old cases (Fig. 4), but this pattern was

\begin{tabular}{|c|c|c|c|c|c|c|c|}
\hline \multirow[t]{2}{*}{ Thyroid measurements ${ }^{\text {a }}$} & \multirow[t]{2}{*}{ Total } & \multirow[t]{2}{*}{ Male } & \multirow[t]{2}{*}{ Female } & \multicolumn{2}{|c|}{ Sex differences ${ }^{b}$} & \multicolumn{2}{|c|}{ Correlation with age $^{c}$} \\
\hline & & & & $\begin{array}{l}\text { Mean differ- } \\
\text { ence }\end{array}$ & $\mathrm{p}$ & $\begin{array}{l}\text { Correlation Coeffi- } \\
\text { cient }\end{array}$ & $\mathrm{p}$ \\
\hline Laminae height (mm) & $25.3 \pm 4.2$ & $28.2 \pm 1.8$ & $20.9 \pm 2.2$ & $7.3 \pm 0.4$ & $<0.001 * *$ & 0.226 & $0.023^{*}$ \\
\hline Laminae breadth (mm) & $36.6 \pm 4.9$ & $39.2 \pm 3.6$ & $32.7 \pm 4.0$ & $6.5 \pm 0.8$ & $<0.001 * *$ & 0.169 & 0.094 \\
\hline Superior horn (mm) & $17.5 \pm 1.9$ & $18.5 \pm 1.7$ & $16.1 \pm 1.7$ & $2.3 \pm 0.3$ & $<0.001 * *$ & 0.153 & 0.129 \\
\hline Inferior horn (mm) & $10.6 \pm 1.4$ & $11.4 \pm 1.1$ & $9.6 \pm 1.3$ & $1.7 \pm 0.2$ & $<0.001 * *$ & 0.058 & 0.567 \\
\hline Total height (mm) & $37.1 \pm 4.1$ & $38.5 \pm 3.6$ & $35.0 \pm 4.0$ & $3.5 \pm 0.8$ & $<0.001 * *$ & 0.085 & 0.400 \\
\hline Upper width (mm) & $47.1 \pm 4.4$ & $48.8 \pm 3.7$ & $44.4 \pm 3.9$ & $4.4 \pm 0.8$ & $<0.001 * *$ & 0.156 & 0.120 \\
\hline Lower width (mm) & $40.3 \pm 3.9$ & $41.6 \pm 2.7$ & $38.3 \pm 4.6$ & $3.3 \pm 0.7$ & $<0.001 * *$ & 0.147 & 0.143 \\
\hline $\begin{array}{l}\text { Anterior border height } \\
(\mathrm{mm})\end{array}$ & $16.5 \pm 2.7$ & $17.6 \pm 1.3$ & $14.8 \pm 3.4$ & $2.8 \pm 0.5$ & $<0.001 * *$ & 0.071 & 0.482 \\
\hline Thyroid notch depth (mm) & $12.3 \pm 2.6$ & $13.2 \pm 2.9$ & $11.0 \pm 1.1$ & $2.1 \pm 0.5$ & $<0.001 * *$ & 0.198 & $0.049 *$ \\
\hline Thyroid angle (degree) & $85.0 \pm 4.6$ & $83.8 \pm 4.8$ & $87.0 \pm 3.7$ & $3.2 \pm 0.9$ & $<0.001 * *$ & 0.094 & 0.350 \\
\hline
\end{tabular}

a. Measurements are shown as mean $\pm \mathrm{SD}$.

b. Measurements are compared between males and females using independent sample t test.

c. Correlation of measurements with age was calculated using Pearson's correlation test regardless of gender.

*p value less than 0.05

$* *$ p value less than 0.01

Table 2. Radiographic features of the thyroid cartilage ossification in different age groups presented as mean $\pm \mathrm{SD}$

\begin{tabular}{lcc}
\hline Age group & Ossified volume $\left(\mathrm{mm}^{3}\right)$ & Hounsfield score $(\mathrm{HU})$ \\
\hline $20-29$ & $5.1 \pm 1.5$ & $281.3 \pm 39.8$ \\
$30-39$ & $5.4 \pm 2.1$ & $289.9 \pm 62.5$ \\
$40-49$ & $5.7 \pm 1.4$ & $296.7 \pm 49.7$ \\
$50-59$ & $6.1 \pm 1.6$ & $302.1 \pm 52.1$ \\
$60-69$ & $6.5 \pm 1.2$ & $329.6 \pm 49.9$ \\
$70-79$ & $6.6 \pm 1.6$ & $332.7 \pm 42.9$ \\
$80-89$ & $5.8 \pm 2.7$ & $287.6 \pm 63.5$ \\
Total & $6.1 \pm 1.7$ & $308.8 \pm 53.5$ \\
p value (with age groups) ${ }^{\text {a }}$ & 0.331 & 0.063 \\
p value (with age) ${ }^{b}$ & $0.040^{*}$ & $0.029^{*}$ \\
\hline
\end{tabular}

a. The comparison between radiographic features and age groups was calculated using 1-way ANOVA test. 


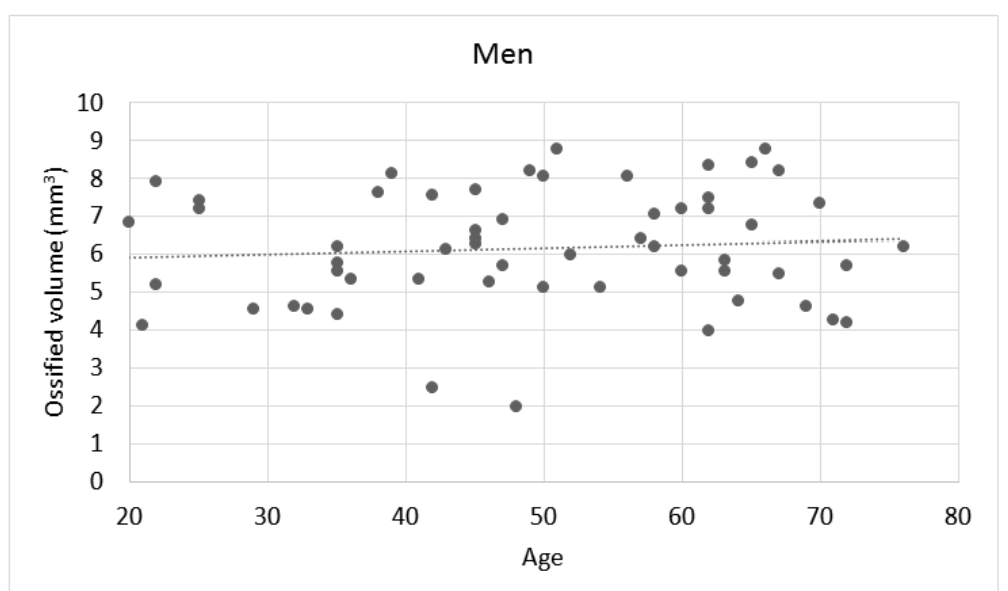

Fig. 2. Scattered plot of the thyroid cartilage ossified volume measured by $\mathrm{CT}$ imaging and age in men

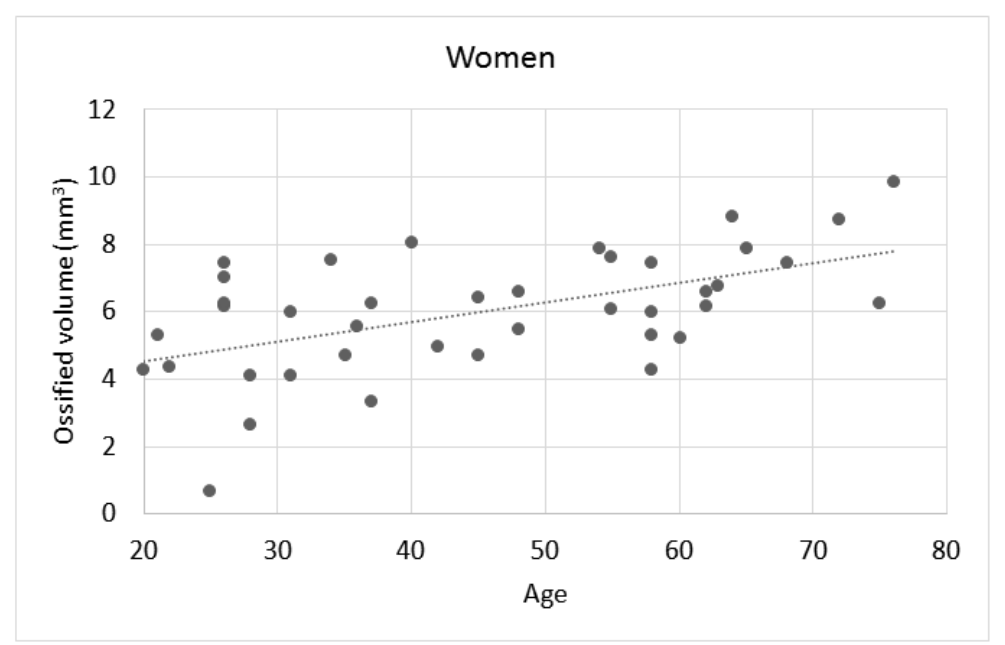

Fig. 3. Scattered plot of the thyroid cartilage ossified volume measured by CT imaging and age in women

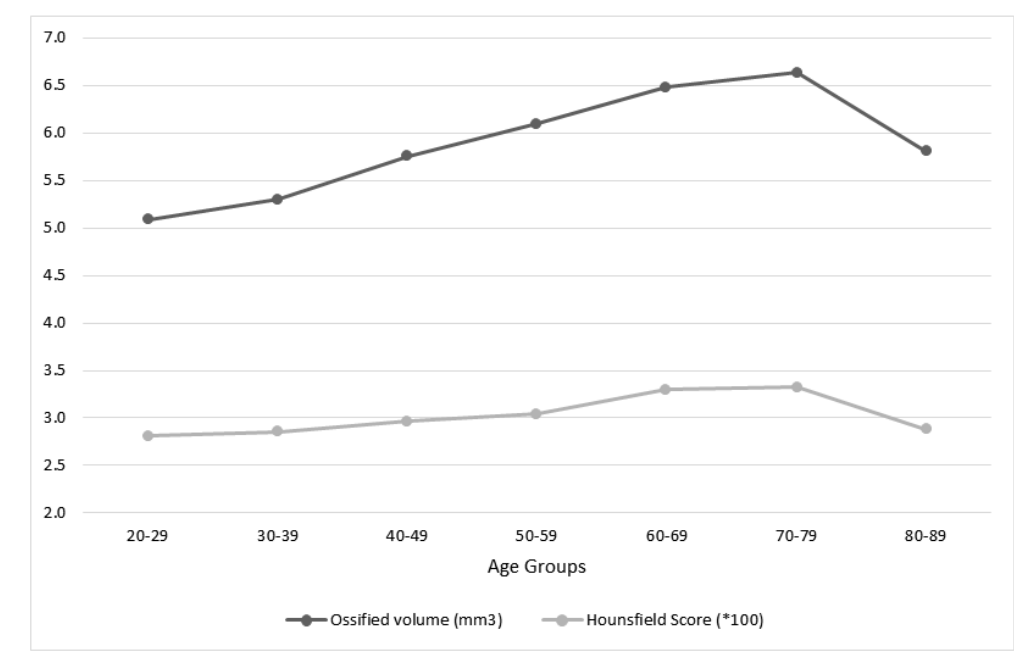

Fig. 4. Mean ossified volume and Hounsfield score of thyroid cartilage measured by CT imaging in different age groups

not statistically different $(\mathrm{p}=0.063)$. However, by excluding cases in 20-29 age group ( $n=3)$ and 80-89 age group $(n=8)$, the $\mathrm{p}$ values were 0.174 and 0.042 for the volume and
Hounsfield score, respectively. There was no significant correlation between body mass index (BMI) and the ossified volume $(\mathrm{R}=0.04, \mathrm{p}=0.656)$ or the Hounsfield score 
$(\mathrm{R}=0.158, \mathrm{p}=0.115)$.

Moreover, the pattern of ossification was assessed with 3D processing of all images. Foci of ossification was observed in the superior and inferior horn in the majority of the younger cases in their 20s and then appeared in lateral borders of cartilage in older cases in their 40s. Ossification mostly involved inferior border to the mid part of cartilage spreading highly through laminae in those who were in their 60s. Surprisingly, less foci of ossification was observed in some cases who were at their $80 \mathrm{~s}$. Although the ossification foci were seen through the cartilage and these ossifications increase with age, there was no specific pattern in different age groups and several cases did not obey these patterns. In addition, 3D images showed that most of these ossification foci are at the surface of the cartilage, not involving the depth of the cartilage, and 2-dimensional patterning could not conclude all cases.

\section{Discussion}

Identification is an important aspect in forensic medicine, and age and sex estimation are 2 considerable fields. As cartilage ossification progresses by aging, it can be an indicator for age estimation. In 1993, laryngeal cartilages were suggested as useful tissues for estimating age, according to its microscopic and radiologic features $(15,16)$. In 1995 , radiographic processing of the thyroid cartilage yielded to $80 \%$ accuracy in estimating age with confidence interval of 8 years (17). After this study, which had concentrated on Japanese cases, a study on French cases revealed that CT scan imaging of the thyroid cartilage has considerable correlation with age, but their findings were insufficient to present a method for estimating age $(1,11)$. Although most studies used plain radiography $(5,15,18)$ and worked on laryngeal cartilages $(12,15,19)$, CT imaging of thyroid cartilage can improve the results and calculations. To avoid any calculation error related to other calcified tissues such as calcified lymph nodes, atherosclerotic plaques or foreign bodies $(20,21)$, neck images were not used.

This study suggests that combining macroscopic anthropometric parameters of the thyroid cartilage with Hounsfield score, obtained from CT scan processing, can be useful to determine gender and age. In this study, all the measured anthropometric parameters were significantly different in men and women, which is consistent with other studies. Poletaeva in similar investigation on thyroid cartilage showed that all characteristics of thyroid cartilage in men are higher than in women, except for thyroid angle (22). Similar studies on Indian and Brazilian population showed similar results $(6,7)$. This information guides us to use anthropometric characteristics of thyroid cartilage to determine sex as a tool in identification.

In this study, it was found that although the laminae height and the depth of thyroid notch were significantly different at different ages, these correlations were not significant for estimating age. On the other hand, ossified volume and Hounsfield score were 2 considerable CT scan findings in estimations of this study. Although the so-called measures were not significantly different in genders, both the Hounsfield score and the ossified volume had correla- tions with age. Dang-Tran et al showed that Pearson's correlation coefficients were 0.73 and 0.75 for men and women, respectively (1). Although our results are consistent with Dang-Tran et al, this correlation was much weaker in the present study and there was no such correlation in men. In contrast with other studies, the present study did not find any difference between the volume of ossification in women and men $(1,18,23)$, which is a new finding.

The Hounsfield score had an ascending pattern in age groups, except for the 80-89 age group. On the other hand, after removing 2 extreme age groups (20-29 age group with 3 cases and 80-89 age group with 8 cases), a p value of 0.042 was obtained. The results of other studies show that ossification changes stop or regress over middle ages $(10$, 24). Although it was observed that the increasing pattern continued till 70s, Aramaki et al (11) did not find such a pattern in those over 50 years.

In this study, some common patterns were observed in ossification of thyroid cartilage within age groups, but these patterns could not conclude all cases. Vlcek (25) and Turk (15) designed a classification that would estimate age based on ossification pattern, but this classification was examined in subsequent studies and found to be inadequate (1). The difference between $2 \mathrm{D}$ and $3 \mathrm{D}$ views are responsible for this discrepancy. In the 3D images, there were various superficial ossification in the absence of deep ossifications which could confuse such modeling. Aramaki (11) reported such ossification in the superior horn of thyroid cartilage, but our results showed several foci of superficial ossification through cartilage. Further histological and 3D modeling are needed to reach better conclusions.

However, this study showed that some anthropometric features of the thyroid cartilage and its Hounsfield score through CT scan imaging can help estimate age, but the accuracy of such methods is not sufficient. Thus, future studies should concentrate on different races, larger populations with lower diversities, and accurate computer 3D modeling, and probably other demographic information to estimate age.

\section{Conclusion}

No single measure from thyroid cartilage is acceptable for age estimation. Although thyroid cartilage parameters are precise enough for sex determination, a combination of anthropometric measures such as the height of the laminae and depth of the thyroid notch with CT scan imaging measures such as ossified volume and the Hounsfield score are need to estimate age. Nevertheless, the accuracy of such methods is not enough.

\section{Ackmowledgment}

The authors wish to acknowledge the Radiology Department of Payambaran hospital, especially Dr, Emad Hosseini for valuable assistance.

\section{Conflict of Interests}

The authors declare that they have no competing interests. 


\section{References}

1. Dang-Tran KD, Dedouit F, Joffre F, Rougé D, Rousseau H, Telmon N. Thyroid cartilage ossification and multislice computed tomography examination: a useful tool for age assessment? J Forensic Sci. 2010;55(3):677-83.

2. Ritz-Timme S, Cattaneo C, Collins M, Waite E, Schütz H, Kaatsch HJ, et al. Age estimation: the state of the art in relation to the specific demands of forensic practise. Int J Legal Med. 2000;113(3):129-36.

3. Arany S, Iino M, Yoshioka N. Radiographic survey of third molar development in relation to chronological age among Japanese juveniles. J Forensic Sci.. 2004;49(3):JFS2003372-5.

4. Grévin G, Bailet P, Quatrehomme G, Ollier A. Anatomical reconstruction of fragments of burned human bones: a necessary means for forensic identification. Forensic Sci Int. 1998;96(2-3):129-34.

5. Thadathil RP, Ponnappan P. Estimation of age from ossification changes in thyroid cartilage of North Kerala population. J Evid Based Med Healthc. 2017;4(70):4158-63.

6. Longia GS. Anthropometrical features laryngeal cartilages. Adli Tip Derg. 1990;6:141-48.

7. Jotz GP, Stefani MA, da Costa Filho OP, Malysz T, Soster PR, Leão HZ. A morphometric study of the larynx. J Voice. 2014;28(6):668-72.

8. Jain M, Dhall U. Morphometry of the thyroid and cricoid cartilages in adults on CT scan. J Anat Soc India. 2010;59(1):19-23.

9. Subramanyam S, Murali G, Mandal S, Bansal Y, Singh D. Sex determination from anthropological measurements of thyroid cartilage in the population of Punjab. J Indian Acad Forensic Med. 2014;36(4):367-70.

10. Claassen H, Schicht M, Sel S, Paulsen F. Special pattern of endochondral ossification in human laryngeal cartilages: X-ray and light-microscopic studies on thyroid cartilage. Clin Anat. 2014;27(3):423-30.

11. Aramaki T, Ikeda T, Usui A, Funayama M. Age estimation by ossification of thyroid cartilage of Japanese males using Bayesian analysis of postmortem CT images. Leg Med (Tokyo). 2017;25:29-35.

12. Garvin HM. Ossification of laryngeal structures as indicators of age. J Forensic Sci. 2008;53(5):1023-7.

13. Vlcek E. Estimation of age from skeletal material based on the degree of thyroid cartilage ossification. Soud Lek. 1980;25(1):6-11.

14. Eckel H, Sittel C, Zorowka P, Jerke A. Dimensions of the laryngeal framework in adults. Surg Radiol Anat. 1994;16(1):31-6.

15. Turk LM, Hogg D. Age changes in the human laryngeal cartilages. Clin Anat. 1993;6(3):154-62.

16. Pigolkin YI, Poletaeva MP, Zolotenkova GV, Volkov AV. [The agespecific changes in the histological structure of the thyroid cartilage in the men]. Sud Med Ekspert. 2017;60(5):11-4.

17. Sugiyama S, Tatsumi S, Noda H, Yamaguchi M, Furutani A, Yoshimura M. Estimation of age from soft X-ray findings of Japanese females thyroid cartilages. Nihon Hoigaku Zasshi. 1995;49(4):236-41.

18. Mupparapu M, Vuppalapati A. Detection of an early ossification of thyroid cartilage in an adolescent on a lateral cephalometric radiograph. Angle Orthod. 2002;72(6):576-8.

19. Sprinzl GM, Eckel HE, Sittel C, Pototschnig C, Koebke J. Morphometric measurements of the cartilaginous larynx: An anatomic correlate of laryngeal surgery. Head Neck. 1999;21(8):743-50.

20. Cunningham C, Scheuer L, Black S. Developmental juvenile osteology: Academic Press; 2016.

21. Yeager VL, Lawson C, Archer CR. Ossification of the laryngeal cartilages as it relates to computed tomography. Investig Radiol. 1982;17(1):11-9.

22. Poletaeva MP. [The possibilities for sex determination based on the specific anatomical features of the human thyroid cartilage]. Sud Med Ekspert. 2017;60(4):21-4.

23. Keen J. Ossification of the thyroid, cricoid and arytenoid cartilages. S Afr J Lab Clin Med. 1958;4:83-108.

24. Sugiyama S. Soft X-ray findings of Japanese thyroidal cartilages with aging. Jpn J Legal Med. 1982;36:645-53.

25. Vlcek E. Odhad stari jedince stanoveny na kosternim materialu podle stupne osifikace chrupavky stitne. Soud Lek. 1980;25(1):6-11. 